\title{
Goods and Persons, Reasons and Responsibilities
}

\author{
Des Gasper \\ Institute of Social Studies, The Hague, The Netherlands
}

Pre-final version of a paper which appeared in International J. of Social Economics, 34 (1/2), 618, in 2007, as overview paper for a special issue:

- 2007: Living In Common and Deliberating In Common - Foundational issues in sustainable human development and human security. International Journal of Social Economics (Emerald), 34 (1/2), 5-126. Co-edited P.B. Anand and D. Gasper. Contributions by J. Ballet, J. Cameron, S. Deneulin, J-L. Dubois, T. Forsyth, S. Karlsson, R. Mahieu.

\begin{abstract}
:
Purpose: An exploration of themes that interconnect six studies in environmentally and socially sustainable human development.

Findings: As humanity threatens to undermine its habitat, a social economics returns to core concepts and themes that became expunged from neoclassical economics: serious examination of persons, seen as more than given points of desire; a broadened perspective on types of good, including a non-neoclassical conception of public goods as publicly deliberated priority goods that are not well managed through free markets and 'common goods' as shared bases vital for everyone; study of what commodities and goods do to and for people; a central role for public reasoning about which are public priority goods, rather than using only a technical definition of a public good; an acceptance of notions of ethical responsibility and responsibilities concerning the provision and maintenance of public priority goods determined through public reasoning; and attention to institutional formats for such deliberation. Amongst the greatest of public priority 'goods' are the concepts of common good and responsibility.
\end{abstract}

Research Implications: The findings reinforce the agenda of socio-economics for central attention to the mutual conditioning of economy, society, polity, and environment, including analysis of the sociocultural formation of economic actors and of ideas of 'common good'.

Originality/value: Cross-fertilization of theorization with cases from Costa Rica, Kenya, Nepal, Thailand, Rwanda, sub-Saharan Africa and global arenas.

Keywords: Common good; Personhood; Public deliberation; Public goods; Responsibility Type of paper: Conceptual paper, General review 


\section{Introduction}

At the start of the $21^{\text {st }}$ century, humankind faces 'interesting times'. Global climate change linked to a carbon-rich lifestyle threatens to eliminate various small island states, destabilise many countries and bring spillover effects that will rock even the richest. Distress and ambition, widening comparisons and growing expectations fuel global-wide drives for respect, for consumption, for status and even predominance. These factors can fuel angry conflicts, intra-national and trans-national. The potential for larger conflagrations seems to increase. Presentday violent conflicts are already frighteningly large in impact: an estimated three to four million people have died prematurely since the mid 1990s in the wars in the former Zaire, now Democratic Republic of Congo. In its small neighbour, Rwanda, following a fall of around $40 \%$ in national income per capita (in US dollar terms) as a result of world market shifts (Eriksson et al., 1996) some Rwandans suffered yet greater declines, for example losing their land or job, as an IMF-designed economic programme enforced 'structural adjustment' on this fragile society. Many lost their lives, or their souls, as the country was then led into an Armageddon of scape-goating; between half a million and a million people were chopped and bludgeoned to death in a matter of weeks in 1994. A metaphor used locally was 'crushing the cockroaches'. Ballet, Mahieu and Radja (this issue) show how 'economic adjustment' contributed to 'identity shift', followed by ethnic 'cleansing'. The effects of such disintegration will not be kept for ever far from the fortresses of the rich, suggests the human security paradigm (UNDP 1994): discontents, diseases, drugs, criminal networks, weapons, violent practices and refugees are all liable to spread.

Living together in peace requires deliberating together, and some acceptance of being participants in a common human enterprise. Not only should rules and agreements be kept concerning foreseen cases and contingencies; people must be able to together constructively face unexpected risks and challenges. Living together involves more than is assumed in many 'rational choice' models of the interaction of myriads of calculating individuals, each considered to be completely pre-formed and purely self-interested. The standard picture in prominent strands of business and management thinking, and in the associated social science, is a world of 'Missing Persons' (Douglas \& Ney 1998). People are treated purely as economic agents, acquisitive individuals whose primary characteristic is a personal set of given preferences, which they calculatedly seek to fulfil. They are not real persons, formed from birth within society and potential participants in its processes of political management, including concerning the formation and negotiation of preferences, processes that involve far more than a bargaining between fixed packages of desires.

The title of this overview paper reflects two studies that appeared in 1984 and have helped to bring some reorientation of thinking in social economics and social philosophy, coincidentally both written by Fellows of All Souls College, Oxford: the economist Amartya Sen's Goods and People and the philosopher Derek Parfit's Reasons and Persons. Through a series of conundrums, about for example how we should consider future generations, Parfit forced analysts to review the natures of rationality, identity, and moral reasoning. He introduced a classification of existing conceptions of 'What Makes Someone's Life Go Best' hedonistic theories, desire-fulfilment theories, and objective list theories - which helped to trigger and organise some of the subsequent investigations into the nature of well-being. His 
work employed perhaps a subtler conception of persons than Sen's - note his very use of the term 'persons' rather than 'people'-yet Sen's work as a whole has pushed the conceptualisation of well-being and its determinants further. 'Goods and People' made a claim about ends, namely that what is important is not the amounts of economic goods sold but how people live and can live. In a classic sister paper, 'Rational Fools', Sen (1977) discussed the persons who hold and pursue ends. Parfit was a pure Oxford philosopher, applying a sharp intellect in the seclusion of his study and the cloisters of his college-in intensive interchange with other such thinkers - to query and illuminate basic concepts and premises. Sen represents a marriage of that tradition with the wider and richer materials of the social sciences, drawn not only from the armchair, the cloister and the seminar room but from organisations, movements and experience around the world. 'The world' is understood here in the full sense, not only with reference to economically rich countries.

The papers in this collection follow in the same spirit: probing and reworking basic conceptions in the light of attention to wideranging experience and wideranging theory. The papers are by social scientists whose work is stimulated, tested and enriched both by philosophical investigations, such as exemplified by Sen and Parfit, and by a commitment to interdisciplinary and international comparison and communication, such as represented by Sen amongst others.

\section{Overview of the papers}

The papers are organised and discussed here in relation to two central themes: living in common and deliberating in common. Nearly all the papers deal with both; the emphasis gradually moves from the first to the second theme. Two more strongly theoretical papers take the lead in, respectively, the first and second parts: Deneulin and Townsend for the theme of living in common; and Cameron and Ojha for deliberating in common.

Deneulin and Townsend show the difference between conventional economics concepts of public goods and an older concept of 'the common good'. While the former are necessary so is the latter, which may rest on a more sophisticated understanding of human personality and interaction. This is particularly important for current discussion of global public goods. Two papers on intra-societal violence, by Ballet, Mahieu and Radja, and by Dubois and Trabelsi, illustrate the breakdown of life in common and conversely the requirements of sustaining a life in common, including for some elements of shared identity, acceptance of mutual responsibilities, and appropriate life-skills including for discussion and deliberation. Ballet et al. focus on how people have partly distinctive identities and how these are constituted and can be reconstituted: in other words, how people are persons and can become monsters. Dubois and Trabelsi explore how education could help to consolidate people's formation as responsible citizens who are able to listen and debate in public fora, as opposed to a formation as ready recruits for genocide.

Cameron and Ojha extend this theme of deliberation in common. They head a set of three papers on environmental governance, including also those by Forsyth and Karlsson, that develop methodological and normative themes that have wider relevance than for environment alone. Both Cameron-Ojha and Forsyth look at deliberation in natural environment arenas: at the political frameworks for reasoning that set who are included or 
excluded, on what terms, and by what means. Karlsson looks at alternative principles for allocating responsibilities for public bads. Her focus on issues that cross national borders returns us to Deneulin and Townsend's concern with global public goods (and bads). Her conclusion reiterates the central importance of a sense of common good, in order to secure these global public goods.

The papers show the broadening of a 'sustainable development' perspective to cover social, cultural and political environments and values and not only physical environments. Ballet et al. for example apply the precautionary principle to the social environment of markets and polities. Sometimes called a 'sustainable human development' perspective (e.g., Banuri et al 1995), this broadened view is nowadays often and perhaps more effectively described as a 'human security' perspective (CHS 2003). We return to it at the end of the paper. The intervening sections consider in turn the themes in the paper's title: (public) goods, persons, (public) reasoning, and allocation of responsibilities.

\section{Goods}

Most introductory economics textbooks present a picture of the organisation of 'the material aspects of social life' that runs as follows. 'Factors of production' are supplied by 'Households' and offered in factor markets where the buyers are the 'Producers' of 'Goods'. These Goods are then sold in product markets, to other Producers (as intermediate goods), or to Households in their role as Consumers which in turn allows the households /consumers to sustain their roles as suppliers of Factors. This simple perspective provides the framework for hundreds of pages of instruction, and indeed typically for several years of university study. Economics is treated as centrally the study of a system of market activity, a system of flows of commodities. Cameron and Ojha mention the attempts to extend such a model into the management of Nepal's currently more community-controlled forests.

Some major limitations of the framework are that: first, it directs primary attention to monetized outputs regardless of their impacts on people; second, it ignores the environments of the system of market activity, and leads to their subsequent admission only in marginal and subsidiary roles; third, it leaves a hole where persons should have been-partly malleable agents who seek to understand and in turn mould their environments, including through constructing and reconstructing discursive orders; and fourth, it suggests by default that a social order is or can be a bargain between a set of preformed individuals.

Goods and the good

A market-centred perspective can give the impression that the social world consists of individuals who exist prior to society and then interact in markets and quasi-markets. In the theoretical model of a perfect market system there is no need for individuals to jointly deliberate, as opposed to self-referentially calculate and bargain, because firstly, Goods (commodities, including time) are the good, and secondly, market mechanisms provide all necessary coordination in the world of goods.

Sen's 'Goods and People' built in contrast on an Aristotelian insight. Rather than presume that Goods are good-let alone take a monetized measure of the circulation of commodities as the central measure of human welfare-we should examine how people 
live: how long, how healthily, how peacefully, how far in accordance with reasoned values; in other words, we should consider what people do with goods and what goods do to and for people. This is, in part, an invitation to deliberate jointly.

Such a perspective has been absorbed into discussions of sustainable development and is why they interface easily with discussions of development ethics, other than in 'deep ecology' views. It makes us ask: sustainability of what? and why? Rather than assuming that maintenance of a particular form of land use is essential, for example, we should look at the sustainability of particular 'environmental functionings' (Tim Forsyth, at the St. Edmund's College workshop) and valued human outcomes. This connects to a conception of public goods as publicly deliberated priorities for maintaining a society.

Public Goods and the underlying notions of the nature of a public realm

Economic activity relies on a social basis and an environmental basis, and also affects both of these. Figure 1 indicates the nesting of systems, and hints at the myriad of interactions. An economic system that undermines its social and environmental bases is unsustainable; for example if it promotes such strong forms of self-interested behaviour that cooperation in providing necessary (global) public goods is undermined or never attained. And while there is considerable tolerable variation concerning what can be managed by market rules, some things which are monetizable should never become subject to the market-body parts, for example, can be bought, as can lives via hiring of contract killers - on grounds both of ethics and, possibly, social sustainability.

Figure 1: The economy in context (source: Gasper 2004)

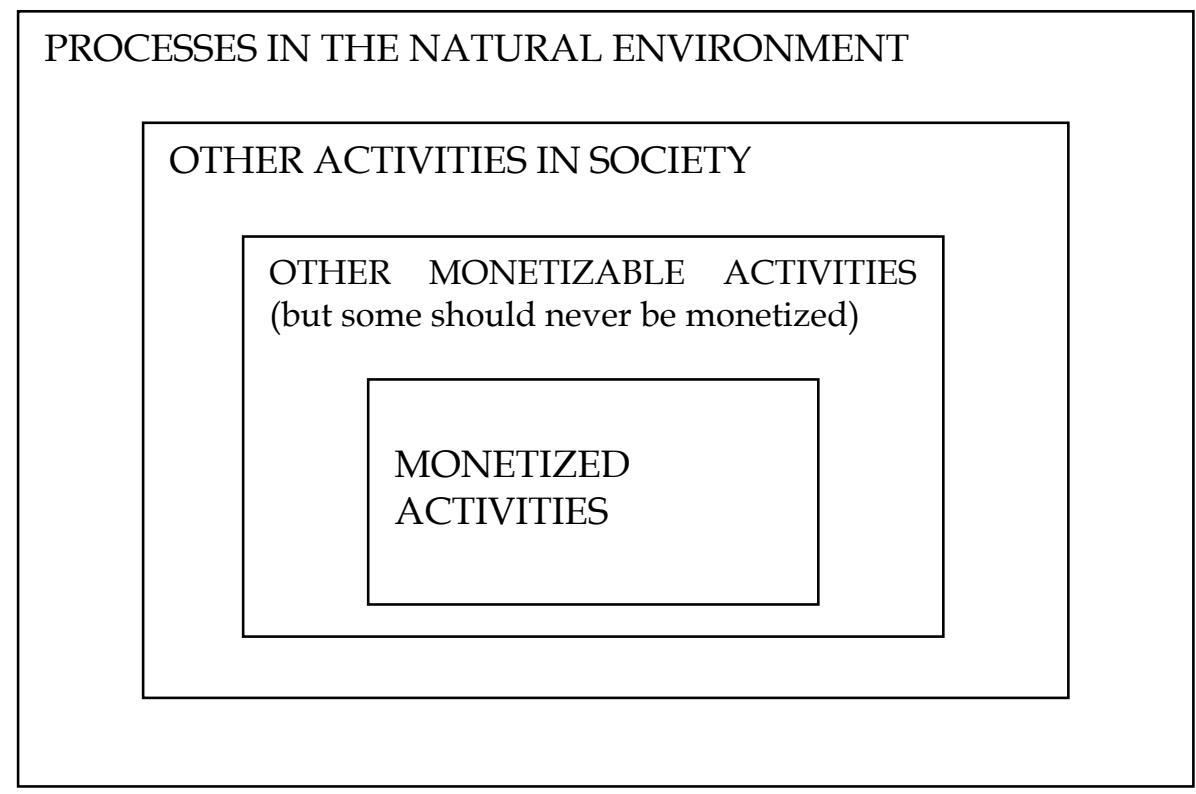

Economic theory addresses the possible effects of the commodity system on its social and physical environments via the category of externalities, one type of 'market imperfection'. Part of the neoclassical economics definition of a public good, by Samuelson (1954), concerns non-excludability: I cannot feasibly exclude you from the benefits (or costs) 
of the commodity I produce, even when you have not purchased it. The other part of the definition concerns non-rivalry: your consumption of the good does not reduce its availability to others. Such a definition of public goods thinks about what is needed for a pure market system to function efficiently: namely, goods that are rivalrous and excludable, such that the prospective consumers have an incentive to pay for them and the prospective producers have an incentive to exclude those who do not pay. 'Public goods' are defined as the opposite, in terms of the same technical dimensions. 'Problematic commodities' would be a better label. The need for public deliberation is not central in this conception.

Many of the 'public goods' which rightly lie at the centre of public attention do not well match Samuelson's definition. Schooling, for example, is both excludable (one can feasibly keep children out) and often rivalrous (more children in the classroom means less attention from the teacher and less share of the resources; and the classroom can become full). Use also of a public facility like a city square or a cathedral is both excludable and potentially rivalrous. Wuyts (1992) points out that public economics covers thus much more than neoclassical public goods. It concerns goods which are deemed of public priority yet not sufficiently supplied through free markets, for example because they have large favourable externalities; regardless of whether they well fit the neoclassical definition. Conversely 'public bads' can include things which have large negative externalities and are oversupplied. The services of well-functioning law courts are a public good - though people could certainly be excluded and the use of courts is rivalrous - if and because they are publicly deemed a priority which is not appropriately supplied on a market basis, and which furthermore has high favourable externalities for those not directly involved.

This alternative conception of public goods-social priority goods that are not well managed through free markets - directs our attention to issues of social prioritization and to who is involved in the deliberations to set priorities. As Sylvia Karlsson noted at the St. Edmund's College workshop, behind the often starkly diverging views between developed and developing countries on what are global public goods and global commons lie value differences, not merely different judgements about excludability and rivalrousness. While peace may be seen as a global, regional, national, and local public good, views differ about the priority of peace in specific locations. Peace in the Congo has received no priority from the dominant global powers.

\section{Common good and common goods}

Severine Deneulin and Nicholas Townsend's paper revives the idea of the common good, and shows that it overlaps with but is not reducible to the neoclassical economics concept of a public good, which does not suffice for analysis of the environmental and institutional bases of human society. Neither irrelevant nor in itself erroneous, the neoclassical concept yet excludes centrally important matters and potentially misdirects our attention. Even the richer category that we have just seen, clarified by Wuyts, de Swaan (1988), Gray (1993) and others, is not designed to embody all the social analysis and varied categories that we require. Should we for example call political and family structures - which can indeed be affected by forms of commercial activity-public goods? We should connect economics to the other social and human sciences, rather than imagine that it can swallow them.

Deneulin and Townsend provide part of the required extension of vocabulary, through 
returning to the classical notion of 'the common good' - the goodness of the life that humans hold in common - and in fact identifying various specific 'common goods'. We noted a type of individualistic vision that neoclassical economics is often associated with: individuals / households exist prior to society, with exogenous preferences; social interaction consists of their bargaining and resultant cooperation and competition; the measure of societal good should be the sum of the fulfilment of the exogenous preferences. This vision takes as exogenous what are in reality endogenous: individuals and their conceptions of the good, of benefits and costs. It thus generates an inadequate conception of the good and of goods, inadequate both for explanation and for human flourishing, perhaps even for human survival. In contrast, Deneulin and Townsend draw on an alternative vision in which people are more profoundly social beings. Let us draw it out explicitly. It contains a series of interconnected but separate ideas, each of them significant, including the following.

- Individuals can only emerge and exist within a society. Requisites for the society's viability, continuation or flourishing might be called elements of 'the common good'.

- Some of these are 'goods' with generally high favourable externalities which are not merely nonrivalrous but which increase in supply when 'consumed', like friendship and love and trust.

- Many vital elements of life in a society can be called 'irreducibly social goods' Charles Taylor's term, employed by Deneulin and Townsend-including most of its culture: language, norms, institutions.

- People's conception of their own good is moulded by social interaction; their values typically flow from a community and from life in that community.

- Further: their conception of 'themselves' is in part-often in large part-social, in that they do not see themselves purely or perhaps even predominantly as individuals, but rather or also as a family member and a member of various groups: of a locality (often more than one), of a profession, of a country, of an ethnic group, of a religion and/or a political tendency, and so on. Using Ballet et al.'s term, their 'identity structure' is complex and social.

- Further still, people's conceptions of the good are social: despite the historical emergence and growth of more individualistic identity structures, these conceptions contain besides a person's own good also the good of others, the good of the community, and a favourable valuation of the life in common. In particular, people put value on: the construction and maintenance of a community or communities; certain values that define the community, including a conception of the right, and of justice, not only of the individual's good in isolation; and affirmation of those values. This is in contrast to the neo-classical conception where, if the exogenous individuals happen to have no concern for their fellows and their descendants, that is viewed as a particular lifestyle choice, rather than as a sign of personal and social pathology.

Just as the public goods concept includes the possibility of 'public bads', so the common good concept must cover 'common bads'. Community itself is not automatically morally good. It is a source of effects, some good, some not.

In discussing the nature of goods we have been forced to consider the nature of the people for whom they are goods. With individuals understood as members within a society, we connect to the Aristotelian conception of well-being for humans: participation in the life 
of the polis, a conception that is given form in contemporary theories of social inclusion and in Doyal and Gough's influential A Theory of Need (1991).

\section{Persons}

People are not calculating machines, idiots savants or 'rational fools' who assess everything except a set of ends that they happen to arbitrarily, idiosyncratically and individually hold. They are imperfectly reasoning, malleable, diverse persons: who become socialised and live within societies, and work within and through sets of cultures, partly discursively constructed systems of meanings; who have limited knowledge and some potential for cooperation and concern for the next generation(s). The societies possess means, less or more democratic or informed, for identification and prioritization of public goods and assignation of social responsibilities.

As we saw, Jérôme Ballet, François-Régis Mahieu and Katja Radja's paper refines the picture by noting that people have multiple aspects of identity, being members of not just a single 'society', for example the grouping which sets formal laws, but of multiple groupings; a point emphasised too by Sen (2006). Sen stresses the choices in prioritisation that people thereby have, and how people highlight different aspects of identity at different times. Besides those sorts of situational emphasising, there can be structural moves of identity: long term trends such as to more individualization, and even relatively sudden shifts. Ballet et al. show how persons' identities can be dangerously re-formed during periods of socioeconomic crisis, such as preceded the 1994 genocide in Rwanda. Their paper distinguishes successive aspects of that tragedy:

- Tensions grew within Rwanda, stemming from increasing demographic pressure, reliance on unstable agricultural export markets, widespread loss of access to land, and extreme and rising inequality.

- Thus, after the coffee market declines of the late 1980s could no longer be cushioned by government subsidies, IMF financial shock therapy in the early 1990s administered shocks that were far more than only financial.

- Political leaders and aspirant leaders turned to appeals to one aspect (ethnic) of felt identity, as a way of mobilising or retaining support, in response to loss of other forms of support as well as an increased felt threat from 1988 in the light of interethnic conflict in neighbouring Burundi.

- The mechanisms of escalation included dehumanization of the other, 'snowballing' of commitment in oppression, and fear of sanctions if one did not participate; leading to hardening of the identity shift and to the move into a 'shock therapy' of another kind: genocide.

- Safety mechanisms failed. 'The international community', so assiduous in imposing financial 'discipline', ignored warnings of imminent disaster, and even long ignored and minimised reports of the actual genocide. Ballet et al. consider the issues of responsibility, and we can ask about the types of 'identity structure' that conduced to irresponsibility.

Jean-Luc Dubois and Milène Trabelsi point out how armed conflicts have legacies that conduce to further violence. Violence violates people emotionally as well as bodily; it can 
destroy good social capital, undermine positive capabilities and build negative ones. They discuss how appropriate schooling and education could reduce the danger of exclusivist, and explosive, types of attitude formation; and more generally how the public goods of appropriate life-skills could support the common good of human security. Ideally, the response to crises could include favourable re-forming of identities. Appropriate life-skills figure in UNESCO's agenda that education should cover 'learning to be' and 'learning to live together', not only acquiring knowledge and learning to do. 'Learning to be' includes, amongst other things, strengthening of a sense of personal responsibility and of skills of resilience. 'Learning to live together' includes understanding interdependence and gaining skills of co-operation and co-determination. Such skills are often especially neglected in secondary and tertiary education. Dubois and Trabelsi are inspired by Sen's capability approach (e.g., Sen 1999). On specific life-skills Sen's generalized treatment says little (see Gasper 2000), but there Martha Nussbaum's more substantive capabilities approach has much to offer (e.g. Nussbaum, 1995, 1997, 2001). In addition a body of work in British education in the 1980s and 1990s that emerged without connection to Sen or Nussbaum also called itself the capabilities approach.

Dubois and Trabelsi remind us that efforts to strengthen positive personal and social capabilities can be readily undermined and outweighed by national and international forces and policies, such as Ballet et al. described. Education on learning to be and learning to live together is therefore not only for direct combatants or potential combatants. National and international decision-makers are priority target groups. They are also key agents for fulfilment of one of the sets of conditions that Dubois and Trabelsi highlight: provision of a common vision for the future that can attract a majority of the people. Uganda offers perhaps a partial recent example, although flawed and fragile. The paper warns that for many leaders the allure of the prizes of war can outweigh training in social responsibilities. The responsibilities of international decisionmakers must then, on the basis of the capacity principle discussed by Karlsson, be activated. In an interconnected world, offering broad economic and educational support-rather than government-assisted export of arms and landmines - is an accumulated obligation as well as a prudential investment.

\section{Reasoning, Risks and Governance}

John Cameron and Hemant Ojha's paper considers more fully than do Dubois and Trabelsi the requirements for a society which treats all members with respect. They apply Kant's ideals of non-coercion and non-deception, but supplement that with reference to realities of social stratification and of encapsulation in group worldviews and practices, where they draw in particular on the insights and formulations of Pierre Bourdieu. Their centrepiece is Jurgen Habermas's vision of reasoned collective deliberation, as an extension of Kant's ideal but also as a possible motor for change. They correspondingly adopt a richer, more realistic, picture of persons than as a set of presocial, fixed atoms of desire. Collective deliberation influences participants and their preferences:

From the perspective of communicative rationality, political agency (or citizenship) is an intersubjective enterprise, as people are connected to diverse networks of communication in 
society. In that sense, they are not autonomous rational beings in themselves, as the ways through which they understand, interpret and channel resources are mediated by intersubjective processes. This reasoning questions aggregative models of liberal governance, which merely add up individual preferences without regard to deliberative principles and collective ethics ... Deliberation is a conscious exercise of communicative competence by social beings to understand, negotiate and transform human relations and ethical norms. [Cameron and Ojha, 2007; this issue]

Cameron and Ojha apply their system of complementary ideas from Kant, Bourdieu and Habermas to forest management in Nepal. They conclude: 'This [Nepal experience] demands reframing of public debate both in procedural and substantive terms procedurally to enhance the agency of the poor and marginalised groups to effectively participate, and substantively to expose deceptive elements in the claims to ethical authority on the part of the dominant technocratic habitus, and the associated element of deception utilised to reproduce social inequality.'

Tim Forsyth's case study complements Cameron and Ojha's. He shows in more detail the mechanisms of technocratic distortion and veiled elite domination in agencies that supposedly defend the common good. Environmental planners and land managers do go beyond a commodity focus to look at effects on environments and, in principle, on people; but they often employ widely generalized 'narratives' about environmental threats, which sustain perceptions of environmental crisis and are used to justify the acquisition or control of natural resources by the State or by capitalist agents, or typically by both in alliance. Research in the past generation has shown that these narratives have often been highly overgeneralized and misleading. Forsyth warns for example of a strong unjustified tendency to assume that physical changes such as erosion and land-cover-clearance automatically constitute problems. His case study from Thailand shows how the orthodox narrative of watershed degradation has been defined by dominant social groups from the lowlands. Yet those social categories-upland and lowland-are too crude to well reflect biophysical reality.

Even the currently popular Sustainable Livelihoods Approach (SLA), which looks at the diverse ways in which rural people construct livelihoods with use of a range of 'capitals' ('natural', 'social', 'financial', 'human', etc.), appears flawed by its imposition of overgeneralized external categories. Critically, Arce (2003) argued that institutional analysts of SLA have confused 'assets' with 'capitals' and have consequently reduced local deliberation because the different kinds of capitals are predefined and imported (Forsyth, presentation to the 2006 St Edmund's College workshop). Bourdieu talks of economic, cultural, symbolic and political capitals, but for purposes of broad understanding not for prescription in specific cases. In contrast, mainstream economics is in key ways a generalized, generalizing discourse - with its grand narrative of 'consumers' and 'producers', and its generalized categories of types of capital - which can conduce to the types of top-down control that Forsyth, Cameron and Ojha criticize.

Forsyth proposes closer attention to the social inclusions and exclusions in the preparation and stabilization of truth claims: who is involved, who is not. The choices of and within intellectual frameworks can either be made with public deliberation included or be concealed within inherited disciplinary formats that often provide cover for the interests of predominant groups. Forsyth makes a case for granting local people, including poor people, 
epistemological respect and involvement in governance of natural resources, given their close experience with specific local realities. 'Thou shalt ensure that the number of voices that participated in the articulation of propositions has not been arbitrarily short circuited.' (Latour, 2003, p. 106; cited by Forsyth at the St. Edmund's College workshop.)

Cameron and Ojha share this view and, drawing on John Dewey, go further. Participation in analysis and decisionmaking can be fruitful in several ways: for reliable and insightful knowledge, for communication and absorption of knowledge, for representation of the interests of the disadvantaged, for building cooperation, capacities and even community, and as ethically valued in itself. Such social learning processes have to be institutionalised. We saw how Cameron and Ojha embed an idealist analysis within Bourdieu's sociology of power and culture. They move towards an enriched conception of Human Development that not merely stresses human agency but sees it as socially moulded, constrained and discursively articulated.

Correspondingly, progress through consensus is far from guaranteed, as many environment cases show. Aware of this, Cameron and Ojha adopt from Bourdieu a second model of change: in addition to change via deliberation, change via crisis, notably cognitive crisis and rethinking. Material crisis sometimes brings rethinking, other times not. The Rwanda experience ominously reminds us that environmental crisis narratives are sometimes in part true, exclusive community affiliations are dangerous, risk and insecurity are subjective and manipulable as well as objective categories, and that the dangers that arise cover not only direct environmental damage but violence leading to multifarious social harm. Nepal is in a longstanding crisis (Blaikie, Cameron and Seddon, 1980). It rests at a crossroads between alternative authoritarianisms and also the perspective of more democratic deliberation that Cameron and Ojha expound and endorse.

\section{Responsibilities}

Using a less painful case (the effects of agricultural pesticides), as suited for development of theory, Sylvia Karlsson considers the allocation of responsibilities for public goods and bads in national and transnational systems. What should be done about transnational public goods? She compares three criteria: culpability, capacity, and concern. Her conclusion is striking: the principles are complementary, but indispensable and for her case central is a sense of living in common and of mutual concern.

By culpability Karlsson refers to causal responsibility, noting though that identifications of culpability involve both a cause-effect analysis and a moral analysis of responsibility. Out of the myriad of contributory conditions to an event only some will be deemed morally relevant. You drive sedately in the correct lane and block my way as I overtake at speed in the wrong lane; you causally contribute to the collision but do not share culpability. Assignations of culpability reflect underlying choices of situation-framing, as shown by Forsyth in his discussion of environmental narratives.

The principle of culpability has major limitations in practice, due to the disputes over both cause-effect linkages and moral relevance. To some people the question of IMF coresponsibility for societal collapse in Rwanda is absurd; to others that responsibility is clear. (Within the IMF itself there was some disquiet and rethinking, though unfortunately no 
cognitive crisis.) This leads us to consider also the principle of capacity. Here, in contrast, the capacity of 'the international community' to have prevented and/or to have later stopped the genocide is indisputable, as indicated by Ballet et al. A combination of capacity, mandate and inaction implies culpable irresponsibility. Lack of responsibility for producing a problem does not mean one lacks responsibility for responding to it. Suppose actor A did not do act D which would have prevented $G$ from happening; that he was capable of doing D or had sufficient chance and capacity to develop that capability (thus one can be responsible for not being able to respond); and that he had the relevant formal responsibility - then his inaction is culpable. While there are dangers of analysing organisations as if they were individuals, one can inquire into the 'identity structure' in governments and international agencies that sit idly by during genocide and similar disasters (see e.g. McNeill and St. Clair, 2006).

Concern-whether directly for others or indirectly for oneself (as in 'enlightened selfinterest'), is the necessary partner and supplement to the principle of capacity. Given the uncertainties in cause-effect chains at global scale, enlightened self-interest too has limited impact. Karlsson concludes that direct concern could be the most powerful criterion, and thus adds an instrumental argument for building of a global ethic or, more modestly put, for strengthening our awareness of and commitment to common goods.

\section{Conclusion}

As humanity threatens to undermine its habitat, a social economics returns to core concepts and themes that became expunged from neoclassical economics: to serious examination of persons, seen as more than points of desire; to a broadened and situated conception of types of good; to study of what commodities and goods do to and for people; to a central role for public reasoning about which are public priority goods, rather than trying to operate with only a technical definition of 'public good'; to an acceptance of notions of ethical responsibility and responsibilities, concerning the provision and maintenance of public priority goods, determined through public reasoning; and to close attention to institutional formats for such deliberation. This paper's outline of the concepts suggested that social persons share some 'common goods', some vital common bases; and that amongst the greatest of public priority 'goods' are the very concepts of common good and responsibility. Much of this is eloquently expressed in Human Security Now, the report of the Commission on Human Security chaired by Sadako Ogata and Amartya Sen (CHS, 2003). The set of papers that follow present arguments and cases-including from Costa Rica, Kenya, Nepal, Thailand, Rwanda, the rest of sub-Saharan Africa, and various global arenas - that sustain and elaborate these contentions.

Acknowledgement: My thanks to P.B. Anand and the contributors to the special issue, particularly Sylvia Karlsson, for their comments on an earlier draft. 


\section{References}

Arce, A. (2003) "Value contestations in development interventions: community development and sustainable livelihoods approaches," Community Development Journal, Vol 38 No 3, pp. 199-212.

Ballet, J., Mahieu, F-R. and Radja, K. (2007), "Destabilising Identity Structures: the impacts of domestic and international policy in the 1994 Rwanda genocide". (In this issue)

Banuri, T., Hyden, G., Juma, C., and Rivera, M. (1995), Sustainable Human Development, From Concept to Operation: A Guide for the Practitioner, UNDP Discussion Paper, United Nations Development Programme, New York.

Blaikie, P., Cameron, J. and Seddon, J. (1980), Nepal in Crisis, Clarendon Press, Oxford.

Cameron, J. and Ojha, H. (2007), “A Deliberative Ethic for Development: a Nepalese journey from Bourdieu through Kant to Dewey and Habermas". (In this issue)

CHS (Commission on Human Security) (2003), Human Security Now, Commission on Human Security, New York.

Deneulin, S. and Townsend, N. (2007), "Public Goods, Global Public Goods, and the Common Good". (In this issue)

Douglas, M. and Ney, S. (1998), Missing Persons, Univ. of California Press, Berkeley: CA.

Doyal, L., and Gough, I. (1991), A Theory of Need, Macmillan, Basingstoke.

Dubois, J-L. and Trabelsi, M. (2007), "Education in Pre- and Post-Conflict Situations: relating capability and life-skill approaches". (In this issue)

Eriksson, John, et al. (1996), The International Response to Conflict and Genocide: Lessons from the Rwanda Experience - Synthesis Report, Copenhagen: Steering Committee of the Joint Evaluation of Emergency Assistance to Rwanda.

Forsyth, T. (2007), "Sustainable Livelihood Approaches and Soil Erosion Risks: who is to judge?". (In this issue)

Gasper, D. (2000), "'Development as Freedom': Moving Economics Beyond Commodities - The Cautious Boldness of Amartya Sen", Journal of International Development, Vol 12 No 7, pp. 9891001.

Gasper, D. (2004), The Ethics of Development: from economism to human development, Edinburgh University Press, Edinburgh.

Gray, J. (1993), Beyond the New Right - Markets, government and the common environment, Routledge, London.

Karlsson, S.I. (2007), “Allocating Responsibilities in Multi-level Governance for Sustainable Development". (In this issue)

Latour, B. (2003), Politics of Nature, Harvard Univ. Press, Cambridge: MA.

McNeill, D., and St. Clair, A. (2006), "Multilateral Institutions, Ethical Discourses, and the Ascription or Avoidance of Responsibility", paper to GARNET workshop, Institute of Social Studies, The Hague.

Nussbaum, M. (1995), Poetic Justice: The Literary Imagination and Public Life, Beacon Press, Boston.

Nussbaum, M. (1997), Cultivating Humanity: A Classical Defence of Reform in Liberal Education. Cambridge, MA: Harvard Univ. Press.

Nussbaum, M. (2001), Upheavals of Thought- - The Intelligence of Emotions. Cambridge Univ. Press, Cambridge.

Parfit, D. (1984), Reasons and Persons, Oxford Univ. Press, Oxford.

Samuelson, P. (1954), "The pure theory of public expenditure", Review of Economics and Statistics, Vol. 36, pp. 387-9.

Sen, A. (1977), "Rational Fools: A Critique of the Behavioural Foundations of Economic Theory," reprinted in Sen, A., 1982, Choice, Welfare and Measurement, pp.84-106. Basil Blackwell, Oxford. 
Sen, A. (1984), "Goods and People". In Sen, A., Values, Resources and Development, Basil Blackwell, Oxford.

Sen, A. (1999), Development as Freedom, Oxford University Press, New York.

Sen, A. (2006), Identity and Violence, Penguin, London.

Swaan, A. de (1988), In Care of the State: health care, education and welfare in Europe and the USA in the modern era, Polity Press, Cambridge.

UNDP (United Nations Development Programme) (1994), Human Development Report 1994, Oxford University Press: New York.

Wuyts, M. (1992), "Deprivation and Public Need", in Wuyts, M., Mackintosh, M. and Hewitt, T. (eds), Development Policy and Public Action, Oxford Univ. Press, Oxford, pp. 13-37. 